\title{
Research on High Quality Development Evaluation of Pearl River Delta Urban Agglomeration
}

\author{
Wang Erwei ${ }^{1, a}$, Liao Aihong ${ }^{1, b^{*}}$ \\ ${ }^{1}$ Zhuhai Campus, Beijing Institute of Technology, Zhuhai, Guangdong, China \\ awodezazhi@126.com \\ b*aihongliao@126.com
}

\begin{abstract}
Based on the new development idea,this paper studies the connotation of high quality development and constructs the high quality development evaluation index system. The high quality development level of nine cities in the Pearl River Delta is calculated. Through horizontal comparative analysis, this paper focuses on the advantages and disadvantages of Zhuhai's high-quality development. The results show that: (1) Shenzhen ranks first in the high-quality development level. Guangzhou, Zhuhai, Foshan and Dongguan rank in the middle in terms of high-quality development, and there is little difference in the level of these cities. Huizhou, Zhongshan, Jiangmen and Zhaoqing are relatively low in the highquality development level.(2)The advantages of Zhuhai in high-quality development are mainly reflected in the stronger driving force of innovation, the leading quality of green development, the significant quality advantage of open development, and the continuous improvement of shared development capacity.(3) Zhuhai's weakness in high-quality development mainly include:the foundation of industrial development is relatively weak; the adequacy and balance of high-quality public service resources need to be improved; and the level of open economy needs to be improved. This study can provide decision-making basis for Pearl River Delta cities and similar cities.
\end{abstract}

Keywords: High quality development, new development idea, system of evaluation indicators

\section{珠三角城市群高质量发展评估研究}

$$
\text { 王二威 }{ }^{1, a} \text { 廖爱红 }^{1, b *}
$$

1 北京理工大学珠海学院, 珠海, 广东, 中国

awodezazhi@126.com

b*aihongliao@126.com

\section{摘要}

以新发展理念为依托, 在对高质量发展内涵进行研究的基础上, 构建高质量发展评估指标体系, 对珠三角九个 城市的高质量发展水平进行了测算。通过横向对比分析, 重点分析珠海高质量发展的优势和不足。研究结论主 要有：（1）深圳的高质量发展水平遥遥领先，广州、珠海、佛山、东莞差异不大，居于中间水平，惠州、中 山、江门、肇庆排名相对靠后。（2）珠海在高质量发展中的优势条件主要体现在创新驱动力更加强劲, 绿色 发展质量领先，开放发展质量优势显著，共享发展能力持续完善。（3）珠海在高质量发展方面存在的不足主 要包括产业发展基础较为薄弱, 优质公共服务资源供给充足性、均衡性有待提升, 开放型经济水平有待提升。 本研究可为珠三角城市及相似城市高质量发展提供决策依据。

关键词: 高质量发展, 新发展理念, 评价指标体系

1. 前言

党的十九大报告中明确指出, 我国经济已由高速
增长阶段转向高质量发展阶段。中央经济工作会议也 提出, 要加快形成推动高质量发展的指标体系。在此 背景下，在部署 2018 年工作时，多地不约而同地淡 化 GDP 増长目标, 纷纷布局推动高质量发展。2017 年 
12 月中央经济工作会议指出, 高质量发展, 就是能够 很好满足人民日益增长的美好生活需要的发展, 是体 现新发展理念的发展 ${ }^{[1]}$ 。随后, 国家发改委副主任宁 吉喆就如何落实中央经济工作会议精神提出, 加快形 成推动高质量发展的指标体系、政策体系、标准体系、 统计体系、绩效评价和政绩考核办法, 是一项十分重 要的工作, 要研究建立 “创新、协调、绿色、开放、 共享” 的统计指标体系、测算计算方法和评价办法 ${ }^{[2]}$ 。 目前, 国家有关部门、地方政府及理论学术界等已基 于五大发展理念开展了关于区域发展评估和高质量 发展评价的指标体系研究与测评工作。综合来看, 主 要的研究动态和趋势有: 第一, 对高质量发展的评价 多采用综合指标评价体系。第二, 基于新发展理念对 高质量发展进行评价是研究的新进展, 概念、指标设 置、方法选取等还需要进一步完善。第三, 在高质量 发展时期, 发展目标和要求发生了新的变化, 指标必 然发生变化, 框架和数据也需要更新。高质量发展更 大程度上是我国政府官方的一种提法, 而不是一个严 格的学术概念。本文在对相关表述和文献进行梳理研 究基础上, 总结认为高质量发展是我国经济社会发展 由初级到高级的必经阶段, 具有系统性、动态性和长 期性的特点。高质量发展, 是能够很好满足人民日益 增长的美好生活需要的发展, 是体现新发展理念的发 展, 是创新成为第一动力、协调成为内生特点、绿色 成为普遍形态、开放成为必由之路、共享成为根本目 的的发展。五个维度相互联系、相互贯通、相互促进、 协同发展。本文基于高质量发展内涵, 构建高质量发 展评估指标体系, 对珠三角九个城市的高质量发展水 平进行测算。基于横向对比, 重点分析珠海高质量发 展的优势和不足。

\section{2. 珠三角城市群高质量发展指标体系}

依据五大发展理念构建珠海高质量发展指标体 系。“创新” 解决经济社会发展的动力转换问题, 是 高质量发展的方法和主线; “协调” 解决经济社会发 展的不平衡问题, 是高质量发展的基础和结构; “绿 色” 解决经济社会发展的可持续问题, 是高质量发展 的方向和原则; “开放” 解决经济社会发展的适应性 问题, 是高质量发展的手段和机制; “共享” 解决经 济社会发展的效益分配问题, 是高质量发展的根本落 脚点。 $[3]$

\section{1. 指标选取原则}

一是全面系统原则。指标设置要充分体现中央关 于高质量发展的有关精神及部署要求, 不仅要反映经 济发展的效率和效益, 还要反映经济结构的优化、发 展动力的转换、人民生活质量的改善。二是适用性原 则。指标的选择要符合实际, 统筹考虑准确性、可获 得性和可操作性。三是简洁性原则。选取具有高度代 表性的指标，避免指标设置过于繁复。

\section{2. 指标体系}

\section{2. 1. 一级指标设置}

对照高质量发展的内涵和要求，设立发展基础、 创新发展、协调发展、绿色发展、开放发展、共享发 展六个一级指标。每个一级指标包含若干二级指标, 体现高质量发展不同方面内容的要求。

推进高质量发展必须要有稳定的宏观环境, 如果 经济增速过低或剧烈波动, 必然会引发经济和社会风 险, 即使不调整发展的长期目标, 也可能不得不把工 作的重点放在应对短期挑战上, 不得不把高质量发展 的战略安排束之高阁。因此, 保持经济增长大体稳定 是推进高质量发展的基础。发展基础的质量的评价指 标主要包括经济发展水平和财政收入水平两个一级 指标。

在新发展理念中，创新居首位，尤其令人属目。 科学与清晰地界定创新发展的内涵是进行相关度量 的前提。作为一种国家发展理念, 创新发展的内涵不 仅仅局限于器物层面, 更是一个涵盖了思想、制度和 技术的系统性发展方略。本文将创新指标分为创新投 入、创新产出和创新机制三个方面。

协调发展是习近平总书记坚持以人民为中心发 展思想的重要内容和新发展理念之一。协调发展质量 的评价指标包括产业结构均衡程度和城乡结构均衡 程度两个方面。

绿色发展是在传统发展基础上的一种模式创新, 是建立在生态环境容量和资源承载力的约束条件下, 将环境保护作为实现可持续发展重要支柱的一种新 型发展模式, 是以效率、和谐、持续为目标的经济增 长和社会发展方式，本文参考《珠海市 2019 年国民 经济和社会发展计划》中对生态环境保护的约束指标, 综合绿色发展对各方面的要求, 从资源利用、环境质 量和生态保护三个方面来分析绿色发展。

从开放发展质量来看, 全面开放是内涵式发展的 开放。实现中国经济高质量发展必须在开放经济领域 形成高质量的全面开放新格局。对各城市而言, 较高 的开放发展质量意味着对外贸易和引进外资等方面 均取得较高的发展程度, 因此, 开放发展评价主要包 括贸易发展和投资发展两个方面。

新时期, 共享发展越来越受到重视, 成为考量经 济发展质量的重要指标。共享从字面上理解就是共同 享有、即发展成果由全体人民共享。本文从收入共享、 机会共享和医疗共享三个方面来衡量共享发展水平。

\subsection{2. 二级指标设置}

为保证指标体系的统一公正性, 对 9 个城市设置 二级指标 29 个。为体现指标评价系统的综合性全面 性, 大部分指标来自于《珠海市 2019 年国民经济和 社会发展计划》，另有一部分指标设置为 “综合指数 
型” 指标, 即通过若干个单项指标合成产生, 如 “研 发投入强度”、“城乡收入比”等。

\subsection{3. 权重设置}

客观指标体系总权重按 100\%赋值。经过多次广泛 征求珠海市发改局等相关部门及有关专家的意见, 充 分吸收, 反复研究, 最终确定采用经典、传统、覆盖 面广的德尔菲法对具体分指标进行赋权。

\section{表 1 珠三角城市群高质量发展指标体系}

\begin{tabular}{|c|c|c|c|}
\hline \multirow[b]{2}{*}{$\begin{array}{l}\text { 维 } \\
\text { 度 }\end{array}$} & \multirow[b]{2}{*}{ 一级指标 } & \multicolumn{2}{|l|}{ 二级指标 } \\
\hline & & 指标 & $\begin{array}{l}\text { 权 } \\
\text { 重 }\end{array}$ \\
\hline \multirow{6}{*}{$\begin{array}{c}\text { 发 } \\
\text { 展 } \\
\text { 基 } \\
\text { 础 } \\
15 \%\end{array}$} & \multirow{5}{*}{$\begin{array}{l}\text { 经济发展 } \\
\text { 水平 }\end{array}$} & 人均 GDP & $20 \%$ \\
\hline & & 规模以上工业增加值 & $20 \%$ \\
\hline & & 全员劳动生产率 & $20 \%$ \\
\hline & & $\begin{array}{l}\text { 民间投资占固定资产投资 } \\
\text { 比重 }\end{array}$ & $10 \%$ \\
\hline & & 社会消费品零售总额 & $10 \%$ \\
\hline & $\begin{array}{l}\text { 财政收入 } \\
\text { 水平 }\end{array}$ & $\begin{array}{l}\text { 一般公共预算收入占 GDP } \\
\text { 比重 }\end{array}$ & $20 \%$ \\
\hline \multirow{5}{*}{$\begin{array}{c}\text { 创 } \\
\text { 新 } \\
20 \%\end{array}$} & \multirow{2}{*}{ 创新投入 } & 研发投入强度 & $25 \%$ \\
\hline & & R\&D 人员数 & $15 \%$ \\
\hline & \multirow[b]{2}{*}{ 创新产出 } & 发明专利授权量 & $10 \%$ \\
\hline & & $\begin{array}{l}\text { 每万人有效发明专利拥有 } \\
\text { 量 }\end{array}$ & $20 \%$ \\
\hline & 创新机制 & R\&D 人员数占总就业人员 & $30 \%$ \\
\hline \multirow{5}{*}{$\begin{array}{c}\text { 协 } \\
\text { 调 } \\
10 \%\end{array}$} & \multirow{4}{*}{ 产业结构 } & $\begin{array}{l}\text { 高技术制造业增加值占规 } \\
\text { 模以上工业比重 }\end{array}$ & $20 \%$ \\
\hline & & $\begin{array}{l}\text { 先进制造业增加值占规模 } \\
\text { 以上工业比重 }\end{array}$ & $20 \%$ \\
\hline & & 现代服务业增加值增速 & $15 \%$ \\
\hline & & $\begin{array}{l}\text { 现代服务业增加值占 GDP } \\
\text { 比重 }\end{array}$ & $15 \%$ \\
\hline & 城乡结构 & 城乡收入比 & $30 \%$ \\
\hline \multirow{4}{*}{$\begin{array}{c}\text { 绿 } \\
\text { 色 } \\
20 \%\end{array}$} & 资源利用 & 单位 GDP 能耗下降率 & $20 \%$ \\
\hline & \multirow{2}{*}{ 环境质量 } & 可吸入颗粒物年均浓度 & $30 \%$ \\
\hline & & 空气质量优良天数比例 & $30 \%$ \\
\hline & 生态保护 & 森林覆盖率 & $20 \%$ \\
\hline \multirow{4}{*}{$\begin{array}{c}\text { 开 } \\
\text { 放 } \\
15 \%\end{array}$} & \multirow[b]{2}{*}{ 贸易发展 } & 外贸进出口总额 & $20 \%$ \\
\hline & & $\begin{array}{l}\text { 外贸进出口总额占 GDP 比 } \\
\text { 重 }\end{array}$ & $30 \%$ \\
\hline & \multirow[b]{2}{*}{ 投资发展 } & 实际吸收外商直接投资 & $20 \%$ \\
\hline & & $\begin{array}{l}\text { 实际吸收外商直接投资占 } \\
\text { GDP 比重 }\end{array}$ & $30 \%$ \\
\hline \multirow{5}{*}{$\begin{array}{c}\text { 共 } \\
\text { 享 } \\
20 \%\end{array}$} & \multirow{3}{*}{ 收入共享 } & $\begin{array}{l}\text { 城市居民人均可支配收入 } \\
\text { 增速 }\end{array}$ & $20 \%$ \\
\hline & & $\begin{array}{l}\text { 农村居民人均可支配收入 } \\
\text { 增速 }\end{array}$ & $20 \%$ \\
\hline & & 居民消费价格指数 & $25 \%$ \\
\hline & 机会共享 & 城镇调查失业率 & $10 \%$ \\
\hline & 医疗共享 & 每千常住人口执业医师数 & $25 \%$ \\
\hline
\end{tabular}

注: 表中指标均为正向指标

\section{3. 数据来源与计算方法}

对于指标体系中各维度的二级指标, 采用综合指 数法进行测算, 分为以下四步。(1) 完成数据收集、 审核、确认，对数据缺失的指标进行处理; (2) 对二 级指标值进行标准化处理得到标准化后的值 $y_{i j}$; (3) 二级指标综合加权得到各城市在各个维度 (一级指标) 的得分 $Y_{i}$; (4) 加权合成各维度的发展质量总指数, 即各城市加权评价总分 $Z$ 。综合指数法的计算公式为:

$$
\begin{gathered}
Y_{i}=\sum_{i=1}^{n} w_{i j} y_{i j}(j=1,2,3 \ldots, n=6) \\
Z=\sum_{i=1}^{n} W_{i} Y_{i}(n=6)
\end{gathered}
$$

通过指标标准化与赋权求和, 计算珠三角城市群 各维度发展质量总指数。指标标准化采用原始数据除 以基期平均值的方法，即以 2013 年为基期，计算基 期年份以各地区的平均值为分母，并用其他年份的指 标比上这平均值, 形成相关标准化数据 ${ }^{[5]}$, 然后再根 据各自权重计算各维度发展质量总指数。

各二级指标的基础数据均来自广东省统计局公 开发布的《广东省统计年鉴》，部分指标数据来源于 各城市统计局公开发布的年度统计年鉴及统计公报。 由于 2019 年部分城市指标数据缺失, 因此本文仅对 2014-2018 年高质量发展水平进行分析。

\section{3. 高质量发展指数测算与结果分析}

\section{1. 高质量发展总指数及其结果分析}

各城市高质量发展总指数测算结果见表 2 和图 1 .

\section{表 2 2014-2018 年珠三角城市高质量发展总指数}

\begin{tabular}{|c|c|c|c|c|c|c|}
\hline $\begin{array}{c}\text { 年份 } \\
\text { 城市 }\end{array}$ & 2014 年 & 2015 年 & 2016 年 & 2017 年 & 2018 年 & $\begin{array}{c}2018 \\
\text { 排名 }\end{array}$ \\
\hline 深圳 & 1.76 & 1.86 & 1.96 & 2.04 & 2.14 & 1 \\
\hline 广州 & 1.09 & 1.14 & 1.2 & 1.27 & 1.35 & 2 \\
\hline 珠海 & 1.06 & 1.1 & 1.19 & 1.23 & 1.34 & 3 \\
\hline 佛山 & 1.04 & 1.06 & 1.1 & 1.18 & 1.27 & 4 \\
\hline 东莞 & 1.07 & 1.09 & 1.09 & 1.08 & 1.22 & 5 \\
\hline 惠州 & 0.91 & 0.89 & 0.93 & 0.89 & 0.96 & 6 \\
\hline 中山 & 0.83 & 0.86 & 0.92 & 0.91 & 0.95 & 7 \\
\hline 江门 & 0.74 & 0.75 & 0.75 & 0.76 & 0.81 & 8 \\
\hline 肇庆 & 0.73 & 0.75 & 0.7 & 0.64 & 0.69 & 9 \\
\hline
\end{tabular}




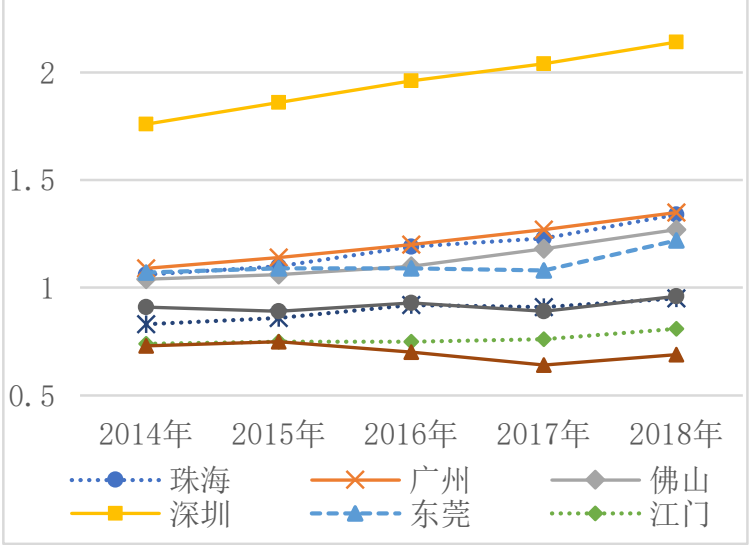

图 1 珠三角城市高质量发展总指数趋势对比

由图 1 可以看出, 珠海市在 2014 年到 2018 年的 高质量发展总指数在珠三角九个城市中处于第三名 的位置, 与排在第二名位置的广州差距较小，其中最 大的差值是 2015 年、2017 年 (相差 0.04)，最小的 差值是 2015 年的 0.01 。珠海市与总指数的第一位的 深圳市相比差异明显, 其中总指数相差最小的年份是 2018 年, 差值为 0.67 。

\section{2. 高质量发展各维度指数及其结果分析}

高质量发展在各维度的指数测算结果见表 3 .

\section{表 32018 年珠三角城市各维度高质量发展指数}

\begin{tabular}{|c|c|c|c|c|c|c|c|}
\hline 城市 & $\begin{array}{c}\text { 发展 } \\
\text { 基础 }\end{array}$ & $\begin{array}{c}\text { 创新 } \\
\text { 发展 }\end{array}$ & $\begin{array}{c}\text { 协调 } \\
\text { 发展 }\end{array}$ & $\begin{array}{c}\text { 绿色 } \\
\text { 发展 }\end{array}$ & $\begin{array}{c}\text { 开放 } \\
\text { 发展 }\end{array}$ & $\begin{array}{c}\text { 共享 } \\
\text { 发展 }\end{array}$ & $\begin{array}{c}\text { 总体 } \\
\text { 评价 }\end{array}$ \\
\hline 深圳 & 2.19 & 4.51 & 1.74 & 1.19 & 1.99 & 0.98 & 2.14 \\
\hline 广州 & 1.74 & 1.83 & 1.11 & 1.1 & 1.06 & 1.15 & 1.35 \\
\hline 珠海 & 1.13 & 2.24 & 0.94 & 1.16 & 1.11 & 1.16 & 1.34 \\
\hline 佛山 & 1.42 & 2.43 & 0.85 & 1.05 & 0.56 & 0.97 & 1.27 \\
\hline 东莞 & 1.14 & 1.73 & 1.21 & 1.1 & 1.01 & 1.03 & 1.22 \\
\hline 惠州 & 0.99 & 0.86 & 1.4 & 1.09 & 0.55 & 0.99 & 0.96 \\
\hline 中山 & 0.9 & 1.32 & 1.05 & 1.04 & 0.36 & 0.94 & 0.95 \\
\hline 江门 & 0.87 & 0.65 & 0.84 & 1.06 & 0.38 & 0.97 & 0.81 \\
\hline 肇庆 & 0.7 & 0.35 & 0.77 & 1.08 & 0.31 & 0.89 & 0.69 \\
\hline $\begin{array}{l}\text { 珠海 } \\
\text { 排名 }\end{array}$ & 5 & 3 & 6 & 2 & 2 & 1 & 3 \\
\hline
\end{tabular}

在六个维度中，与广州市相比，珠海弱势是发展 基础和协调发展维度; 与深圳市相比, 其明显弱势是 发展基础、创新、协调、开放个维度。

在发展基础维度, 珠海市位居第五, 与前三名的 深圳、广州、佛山差距明显, 与深圳市的差距达到了 1. 06。但 2014-2018 年期间, 珠海市发展基础维度的 指数总体处于上升趋势, 说明珠海的发展基础正在不 断壮大。珠海市应夯实实体经济, 继续加大经济、工 业发展的投入。在创新维度上, 珠海市总体上位居第 三, 且指数值近几年在持续稳定的增加, 与创新指数 较高的深圳与佛山市的差距正在不断缩小。在协调维
度上，珠海市排名靠后（排第六），且 2014-2018 年 间指数值波动较为明显，2014 年到 2016 年处于增长 状态，2017、2018 年处于下降状态。在绿色维度上， 珠海市发展较好, 2018 年的指数值处于第二名, 仅次 于深圳市。在开放维度上, 珠海市由 2014-2016 的第 三名上升到 2017-2018 年的第二名。在共享维度上, 除 2017 年外, 珠海市稳居珠三角城市的第一名。

\section{4. 结论}

从新发展理念的角度进行评估本文认为, 珠海在 高质量发展中的优势条件有: 一是创新驱动力更加强 劲。从近几年的创新发展指数走向来看, 珠海市的起 点虽在中等水平，但发展势头非常迅猛，2015 年起稳 居前三名, 且有望在 2019 年后超过第二名的佛山市, 与深圳市齐头并进。政府对珠海的创新领域高度重视, 近几年努力改善创新机制, 研发投入强度稳定保持在 $2.5 \%$ 左右，领先于珠三角大部分城市。二是居于领先 的绿色发展质量。珠海长期坚持绿色发展，污染防治 攻坚战常抓不懈，环境质量多年来一直名列全国前茅， 城市面貌持续更新。珠海现已拥有一流的人居环境, 并作为 “绿色城市样本” 获得诸多殊荣。三是开放发 展质量优势显著。近几年, 在珠三角城市群中, 珠海 市的开放发展指数排名稳居前三。与其他城市相比, 珠海实际吸收外商直接投资占 GDP 比重指标居于领 先地位。横琴自贸区制度创新成果显著, 横琴对优质 发展要素的吸引力进一步增强。珠澳合作进入新阶段, 区域融合更加深入。四是共享发展能力持续完善。主 要体现在公共服务体系持续完善, 持续增加教育、医 疗卫生、文化体育等公共服务供给。通过出台 “促进 就业十条” ，提高保险补贴、津贴、困难补助标准等 举措, 民生底线保障水平持续提升。

珠海在高质量发展方面存在的不足有: 一是产业 发展基础较为薄弱。产业规模较小, 工业长期依靠少 数几家大企业支撑。服务业占比低于全国和全省平均 水平，消费规模偏小。二是优质公共服务资源供给充 足性、均衡性有待提升。教育、医疗、养老、公共文 化、公共交通等优质公共服务供给不足。特别是交通， 尚未形成内畅外联的交通主骨架。村海岛发展与城区 相比仍有较大差距。三是开放型经济水平有待提升。 近年来, 珠海外贸进出口总额增长快, 但总量一直不 大。实际吸收外商直接投资额与广州、深圳相比差距 较大且增速较缓慢。横琴自贸片区相比广东其他两个 自贸片区的发展还存在一定差距。珠海与 “一带一路” 沿线国家、与欧美和拉美国家的合作水平及合作领域 有待进一步深化。

\section{项目基金}

本文为广东省教育科学 “十三五” 规划 2020 年度研究项目《深珠科教融合互动建设湾 区东西两岸合作先行区路径研究》 （2020GXJK207）的阶段性成果之一。 


\section{REFERENCES}

[1] Li J.,Shi L.,Xu A.(2019)Probe into the assessment indicator system on high-quality development. Statistical Research.36:4-14.

[2] Fan J.,Zhang Q.,Luo C.(2018) Evolution trend of economic development quality of Yangtze River Delta urban agglomeration and its countermeasures. Journal of Industrial Technological Economics.37:70-77.
[3] YANG L., LI X.(2020)Evaluation of high quality development in ethnic minority areas of China based on"five development concepts".47:79-88.

[4] Liao A.,(2020)Evaluation of industrial transformation and upgrading in Pearl River Delta-From the perspective of eco economic efficiency. Enterprise technology and development. 08: 12$13+16$.

[5] Su Y.,Chen C.(2019)Construction and demonstration of evaluation index system for high quality economy development. Statistics and Decision. $35: 38-41$. 